\title{
The Characteristic of Variable Frequency Drive for Water Flow Control in the SFC Plant
}

\author{
Sefi Novendra Patrialova ${ }^{1 *}$, Destiarga Husein Wardhana ${ }^{1}$, Lucky Putri Rahayu $^{2}$, Tedy Agasta $^{1}$
}

\begin{abstract}
One of several techniques to control fluid flow-rate through a pump is using variable frequency drive. This paper presents how experiment be able to perceive the characteristic of variable frequency drive (VFD) to control water flow-rate in the Simulator Flow Control (SFC) plant. The SFC plant is developed for a fluid course learning simulator. The user would be able to set the desired value of frequency or flow-rate through a convenient interface. To provide it, the characteristic of VFD-frequencyto-flow-rate must be firstly observed, as reported in this paper. The fluid flow-rate control is designed without an electric valve, but using VFD to drive the 250 Watt water pump. In this first development, the SFC Plant successfully work with various water flow-rate from 2 Liter per minute until 20 Liter per minute by changing the frequency input of VFD. The water flow-rate was measured by manual rotameter, the flow sensor has not been applied yet in this first development. In this experiment, the VFD's frequency was set from $10 \mathrm{~Hz}$ to $36 \mathrm{~Hz}$ with $2 \mathrm{~Hz}$ intervals. Result showed that VFD frequency is proportional to water flow-rate. The higher frequency given to VFD, the faster rotational motor of water pump generated and then given rise to water flow-rate. Using linear graphic approach, the characteristic is shown through the linearity coefficient of 0,68 and constant value of 3.43. This characteristic value would be useful for open-loop-control and user interface programming in next step of development.
\end{abstract}

\section{Keywords - Control system, Instrumentation, Variable frequency drive, Variable speed drive, VFD, Flow control system}

\section{INTRODUCTION}

$\mathrm{C}$ ontrolling fluid flow-rate in a piping system can be executed using several techniques. Adjusting the actuator, such as automatic valve or pump, could be implemented as the solution among these techniques. Controlling flow-rate using automated valves is a priorleading technique which is still being frequently implemented. Unfortunately, many problems occasionally occur from the valve hence the control system unable to meet the performance after working for a long time. It is caused by corrosion or sedimentation if the fluid flowed through it contains chemical suspension. Cavitation and leakage also usually happens in implementation of the automatic valve [1]. Furthermore, restricting flow-rate using valve is able to waste energy when it combined with pump [2]. This kind of resistance device could shortly work perfect to control fluid flow-rate, but it causes a wasting-energy for continuous use. While the pump works at constant speed and power, this resistance device narrowing the cross-sectional area of the flow, then the pressure would increasingly hit the valve. Pressure drop in the downstream flow causes much energy losses [3].

Many industries avoid the implementation of a resistance valve to control the fluid flow-rate. Over $60 \%$ industrial power-use dominated by devices based on motor [4]. Thus, adjusting the angular velocity of the motor pump would be another possible solving. By adjusting the angular velocity of the motor pump using variable frequency drive (VFD), it will impact to the power consumed. Based on many researches, the VFDs enable to reduce the pump power expenditure by $30-88 \%$ [5].

The variable frequency drive (VFD) is an electronic controller which able to vary and control rotational velocity

${ }^{1}$ Department of Instrumentation Engineering, Institut Teknologi Sepuluh Nopember, Kampus ITS Sukolilo, Surabaya, 60111, Indonesia. E-mail: $\underline{\text { sefi@instrum-eng.its.ac.id }}$ of AC/DC motor [6]. VFD also known as Variable Speed Drive (VSD) or sometimes called as inverter [7]. There is three kind of methods which is mostly used in industry, i.e. electrical VFD, mechanical VFD and hydraulic VFD. In this research, we use hydraulic VFD. Based on these three category, hydraulic VFD generally uses to control motor pump and fluid coupling [4]. Many kinds of driver pump which applied in industry, such as diesel engines and steam turbines, yet mostly of pump are moved by electric motors. Here figure 1 is the general schematic for pumping system using VFD.

The lower the frequency generated by the variable frequency drive (VFD), the lower the rotation velocity produced by the motor of pump. So in other words, the lower the speed of motor pump, the lower power would be consumed.

This paper presents how fluid flow-rate was successfully controlled without any electrical valves in the Simulator Flow Control (SFC) plant, but using the variable frequency drive (VFD). The Simulator Flow Control, which is later written in SFC plant, is evolved to support the development of flow sensor research in Instrumentation Engineering Department ITS. To understand the characteristic of VFD for water flow control in SFC plant, the control system applied is an open loop. The flow rate was measured by rotameter which is attached in pipeline.

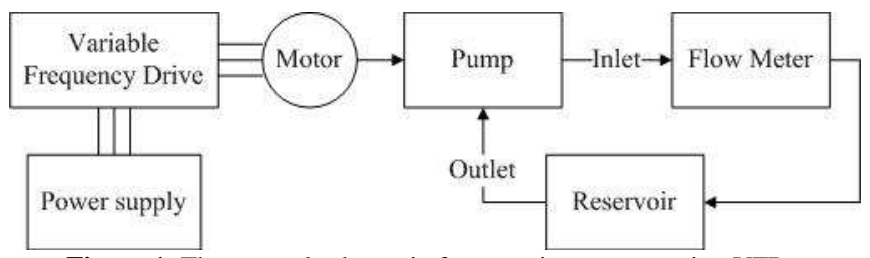

Figure 1. The general schematic for pumping system using VFD

\footnotetext{
${ }^{2}$ Department of Automation Electronics Engineering, Institut Teknologi Sepuluh Nopember, Surabaya, 60111, Indonesia.
} 


\section{METHOD}

\section{A. The Research Flow Chart}

The research procedure is shown in the following figure 2 :

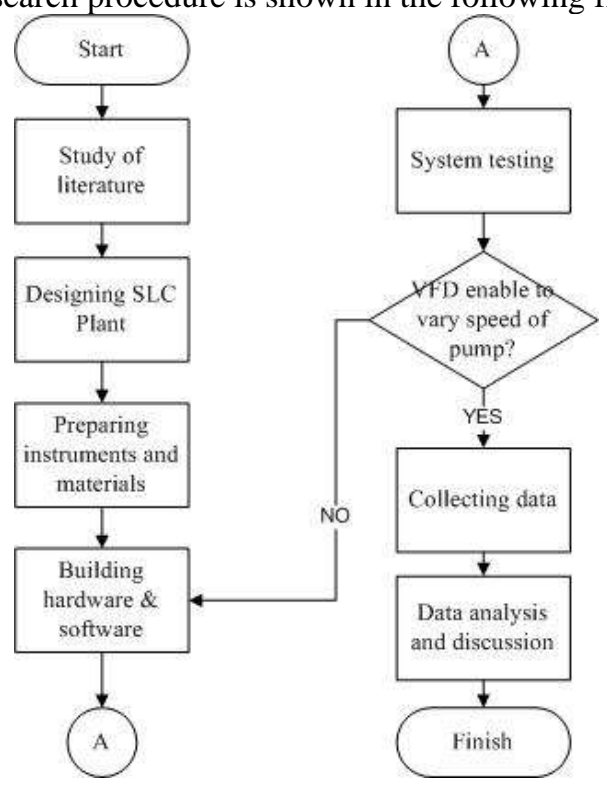

Figure 2. The flow chart of research

The research has been started by identifying problems in several plants in the Instrumentation Engineering Department. In prior development, fluid flow-rate was mostly controlled using a motor operated valve (MOV). However, the most systems do not meet the perfect performance. Through literature studies, flow-rate control using VFD has been known as the better method than using valve. After selecting VFD to control the flow-rate, some modifications were made to the SFC plant. Some instruments or components which used in this study are variable frequency drive (VFD), rotameter, 24 VDC power supply, ATMega8535 Microcontroller, buck converter and PWM to voltage converter.

\section{B. The SFC Plant Design and Specification}

The SFC plant was designed to flow a kind of fluid from the tank in cycles. The tank has capacity for $54 \mathrm{~L}$ of fluid. In this experiment, the 26 LPM pump flowed water through $1 / 2$ " PVC pipe. There also has a rotameter to measure the water flow rate. The rotameter is capable of measuring water flowrates up to $20 \mathrm{LPM}$. To drive a $250 \mathrm{Watt}$ water pump, VFD with 400 watt or 3 horse power (HP) has been used in this research.

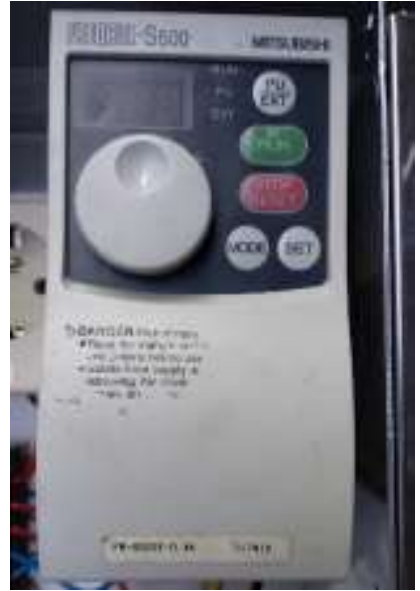

Figure 3. Variable Frequency Drive for SLC Plant

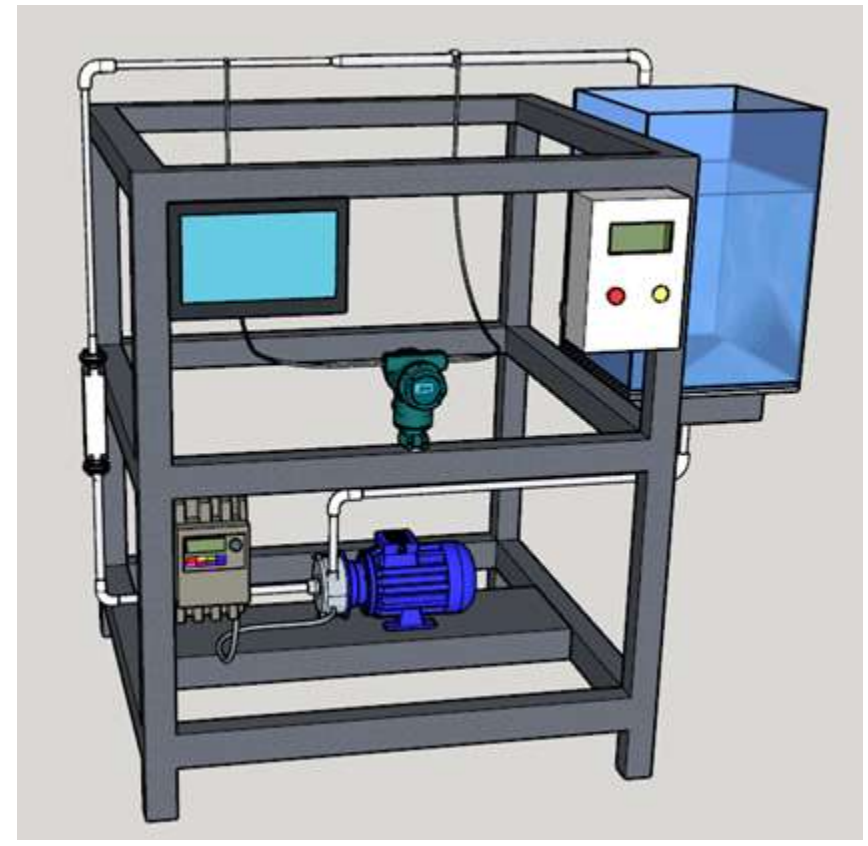

Figure 4. Design of SFC Plants

The design of the SFC plant showed in figure 4 and figure 5 below. Figure 4 is the 3D design of SFC plant, and figure 5 is the piping and instrumentation diagram of it. To control the water flow-rate, the set-point would be adjusted by user requirement. The user could input the desired value of frequency or flow-rate through LCD. Before it, frequency and flow rate had to firstly characterize as reported as in this paper.

In the following figure, there is a Differential Pressure Transmitter (DPT) with two probes. It has been used to recognize the pressure in each section of the pipe. At the SFC plant, there are two kind of pipe diameter along the fluid flow-line, which are designed to apply the concept of fluid continuity. The SFC plant flows water cyclically in this study. The volume of water storage tank in SFC plant was 30 liters. 


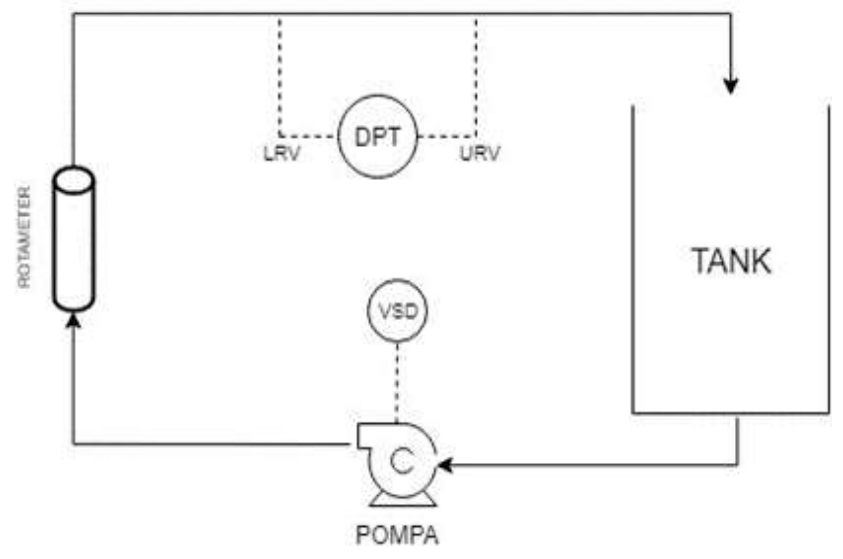

Figure 5. Piping and Instrumentation Diagram Plant Simulator Flow Control

\section{Open Loop Control System for Water Flow-Rate Control in SFC Plant}

The figure 6 is showing the open-loop block diagram of water flow-rate control in SFC plant. There is no flow sensor in this system, but rotameter as a standard flow meter.

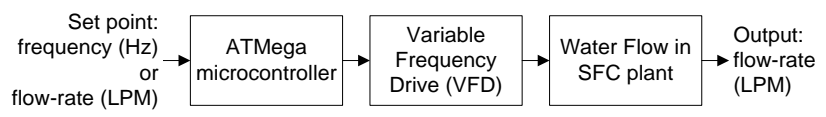

Figure 6. Open-Loop Block Diagram for Water Flow Control in the SFC plant

The block diagram explains the control flow carried out by the VFD (controller). Starting from the variable input is set by user on the HMI as a set-point. There are two modes of set-point to run the SFC plant. Users are able to choose first mode with frequency as set point variable, or another mode with flow-rate as the set point. this variable will be processed in microcontroller. The microcontroller will send signal to the VFD as an actuator. This actuator then will set the rotational speed of the motor and change the flow rate.

To ensure frequency input by the user is same with the real rotational speed of pump, we firstly measure the rotational velocity of pump using a stroboscope. The result of measurement is compared to the frequency input by VFD. The frequency input varied from $10 \mathrm{~Hz}$ to $60 \mathrm{~Hz}$ with $5 \mathrm{~Hz}$ of intervals. Error value between the frequency input of VFD and the stroboscope measurement would be used to calibration process.

After calibrating the rotational speed of pump, the next step was measuring the respond flow-rate using rotameter when user manipulating the input frequency through human machine interface (HMI).

\section{RESULTS AND DISCUSSION}

In the system test, the frequency input are given to the VFD by user, so it can vary the rotation speed of the water pump motor. The test results are shown in the following table
TABLE 1.

TEST RESULTS VARIABLE SPEED DRIVE WITH ROTATING SPEED OF THE PUMP MOTOR

\begin{tabular}{lccccc}
\hline \multicolumn{7}{c}{ Rotational velocity of } \\
pump \\
No & $\begin{array}{c}\text { Frequency } \\
\text { input VSD } \\
\text { (Hz) }\end{array}$ & $\begin{array}{c}\text { Measured } \\
\text { by } \\
\text { Stroboscope } \\
\text { (RPM) }\end{array}$ & $\begin{array}{c}\text { Calculated } \\
\text { based on } \\
\text { Theory } \\
\text { (RPM) }\end{array}$ & Error & $\begin{array}{c}\text { Percentage } \\
\text { of errors }\end{array}$ \\
\hline $\mathbf{1}$ & 10 & 507,4 & 600 & 0,1543 & $15,43 \%$ \\
\hline $\mathbf{2}$ & 15 & 845,2 & 900 & 0,0609 & $6,09 \%$ \\
\hline $\mathbf{3}$ & 20 & 1164 & 1200 & 0,0300 & $3,00 \%$ \\
\hline $\mathbf{4}$ & 25 & 1482 & 1500 & 0,0120 & $1,20 \%$ \\
\hline $\mathbf{5}$ & 30 & 1779 & 1800 & 0,0117 & $1,17 \%$ \\
\hline $\mathbf{6}$ & 35 & 2070 & 2100 & 0,0143 & $1,43 \%$ \\
\hline $\mathbf{7}$ & 40 & 2373 & 2400 & 0,0113 & $1,13 \%$ \\
\hline $\mathbf{8}$ & 45 & 2680 & 2700 & 0,0074 & $0,74 \%$ \\
\hline $\mathbf{9}$ & 50 & 2978 & 3000 & 0,0073 & $0,73 \%$ \\
\hline $\mathbf{1 0}$ & 61 & 3616 & 3660 & 0,0120 & $1,20 \%$ \\
\hline Average & & & & 0,0321 & $3,21 \%$ \\
\hline \hline
\end{tabular}

The table 1 show that frequency input VSD affect to rotational velocity of pump. According to measurement using a stroboscope, the system was successfully increasing the rotational speed of pump from 507,4 to 3616 radian per minute (RPM). To validate that measurement, it was compared by the real value of rotational speed using the following formula.

$$
n s=\frac{120 f}{P}
$$

Where:

$n s=$ rotational synchronous speed of stator pump (RPM)

$f=$ frequency $(\mathrm{Hz})$

$P=$ number of motor poles

The results of calculations based on its formula obtained values between 600 to 3660 RPM. There is the difference between the result of measurement and calculation. It does normally happen and acceptable. We also computed the error values between them. The error value varies by $0.74 \%$ to $15.43 \%$ with an average error of $3.21 \%$. The greater error occurred when the lowest frequency input was applied to the system.

A motor always has the constant value named Slip $(S)$. The slip constant represents the percentage ratio difference value between the synchronous rotation of stator $(n s)$ and rotor $(n r)$ divided by the stator synchronous rotation $(n s)$. The value of the rotor rotational speed $(n r)$ is generally smaller than the stator (ns) [8].

$$
S=\frac{n_{s}-n_{r}}{n_{S}} \times 100 \%
$$

To be able to produce a coupling motor, the synchronous rotation of the stator and motor must not be the same value. That is why, the measured rotational speed values showed in table 1 are different with the calculated, because the speed measured by the stroboscope actually represents the value of 
the rotor rotation $(n r)$, while another calculated value represents the stator synchronous speed $(n s)$.

The following figure 7 is a graph of the relationship between variations in VSD frequency and motor rotation speed at a water pump. In Figure 7, it can be seen that the orange line is the graphic for rotational speed of the water pump motor according to the calculation based on formula (1), while the blue line is for the rotation speed of the pump measured by the stroboscope. Through a linear approach to the graph, a gradient of 60,73 and $\mathrm{R}$ squared of 0,99 was obtained. It means that the system can run the motor speed 60,73 RPM per $1 \mathrm{~Hz}$ frequency input and the goodness of fit in this graphics is at its best.

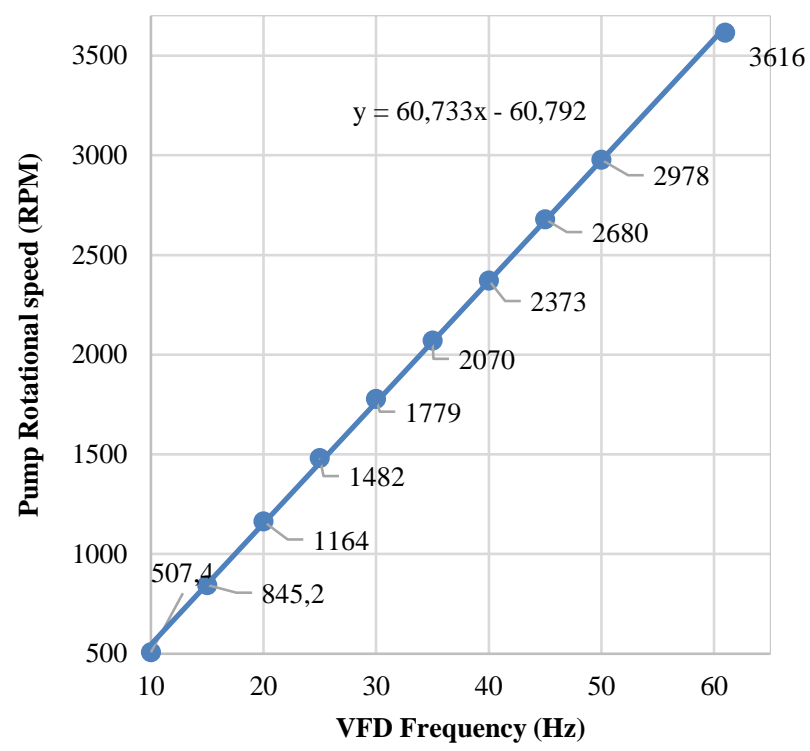

Figure 7. Correlation graph between Variation in Frequency of VSD with Motor Rotational Speed in a Water Pump

After knowing the correlation between frequency input and rotational speed of water pump, then the pump was connected to water pipeline in SFC plant. To know the performance of VFD in cycling water, there is a rotameter installed along the pipeline. The various frequency was set to VFD as its inputs. Considering rotameter specifications, the frequency input can only be varied between $10 \mathrm{~Hz}$ to 36 $\mathrm{Hz}$ with $2 \mathrm{~Hz}$ interval. Table 2 shows the experimental result for knowing the performance of VFD to water flow-rate. Based on this experiments, VFD was successfully vary the water flow-rate in the SFC plant from 2 to 20,2 liter per minute (LPM).

TABLE 2 .

THE RESULT OF EXPERIMENT ABOUT CORRELATION BETWEEN FREQUENCY VFD AND WATER FLOW RATE IN THE SFC PLANT

\begin{tabular}{cccc}
\hline \hline No & $\begin{array}{c}\text { Frequency } \\
\text { input } \\
\text { VFD (Hz) }\end{array}$ & $\begin{array}{c}\text { Water flow-rate } \\
\text { measured by } \\
\text { rotameter } \\
\text { (LPM) }\end{array}$ & $\begin{array}{c}\text { Power } \\
\text { consumed } \\
\text { by pump } \\
\text { (watt) }\end{array}$ \\
\hline 1 & 10 & 2 & 0.29 \\
\hline 2 & 12 & 4,5 & 0.99 \\
\hline 3 & 14 & 6 & 1.84 \\
\hline 4 & 16 & 7,8 & 3.18 \\
\hline 5 & 18 & 9,2 & 4.83 \\
\hline 6 & 20 & 10,7 & 7.01 \\
\hline 7 & 22 & 12 & 9.60 \\
\hline
\end{tabular}

\begin{tabular}{cccc}
\hline 8 & 24 & 13,6 & 13.06 \\
\hline 9 & 26 & 14,8 & 16.79 \\
\hline 10 & 28 & 15,9 & 21.04 \\
\hline 11 & 30 & 17 & 25.95 \\
\hline 12 & 32 & 18 & 31.39 \\
\hline 13 & 34 & 19,3 & 38.15 \\
\hline 16 & 36 & 20,2 & 44.91 \\
\hline
\end{tabular}

Based on the experiment results on table 2 which has been plotted in figure 8, it can be seen that VFD in SFC plant has successfully fulfilled the Affinity Laws in the SFC plant. It means, the implementation of VFD in this SFC plant can also save power/energy.

Referring to the Affinity Laws, rotational speed, flow and power have relationship as shown as these following formula:

$$
Q=N D^{3}=2 \pi f D^{3}
$$

This explains that when rotational speed $(N)$ varies, water flow-rate $(Q)$ will varies directly with it. Also, the power consumed by the pump $(P)$ varies with the cube of the rotational speed of motor $(N)$,

$$
P=\rho N^{3} D^{5}
$$

where $D$ is diameter impeller pump, $f$ is requency and $\rho$ is density[9]. The diameter of impeller pump which applied in this plant is $5,91 \mathrm{~cm}$.

When compared to the use of a throttling device or valve, the use of VFD in the SFC plan is more effective. If a valve is used to control the flow-rate, the flow precisely reduces but the power does not. furthermore, it also increases friction and pressure in the system. This can happen because the rotational speed of the pump motor runs constantly. By using VFD in SFC plant, water flow-rate is good controlled, power consumption by pump is also managed. The power consumed by the pump have been presented in table 2 , based on equation (2) and equation (3). The results show that VFD is able to make the pump work properly with less than 45 Watt of power. It proves that implementation of VFD in this SFC plant can also save power/energy. 


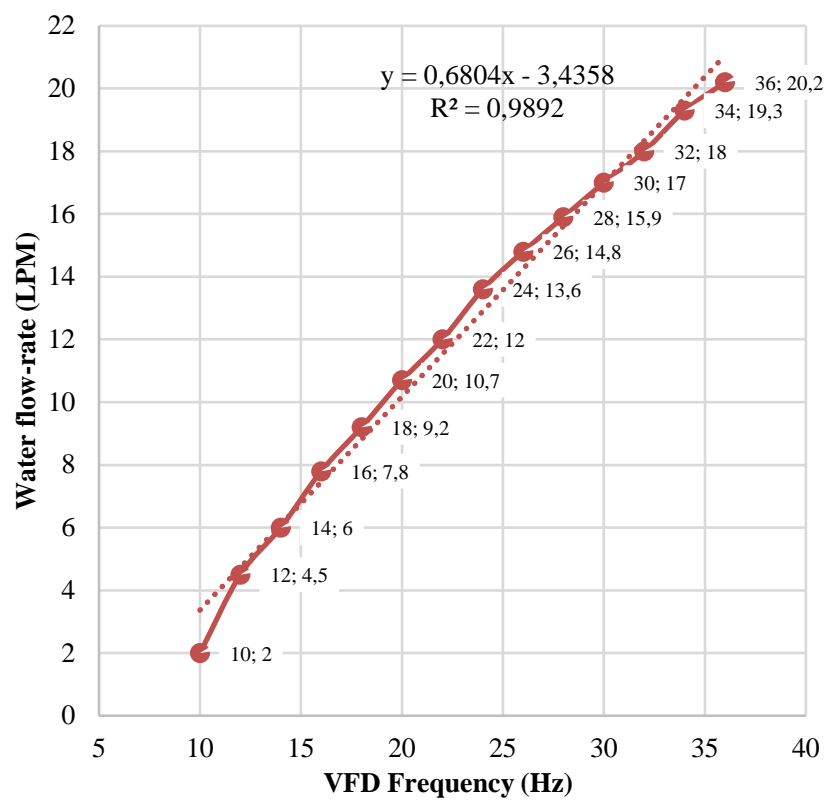

Figure 8. Correlation graph between frequency VFD and water flow rate in the SFC plant

\section{CONCLUSION}

Based on the research has been done, it can be concluded that VFD was successfully fulfill the Affinity Law to control flow-rate in the SLC plant without any throttling valve. The VFD frequency is proportional to water flow-rate. The higher frequency given to VFD, the faster rotational motor of water pump generated and then given rise to water flowrate. Using linear graphic approach, the characteristic of VFD in this SFC plant is shown through the linearity coefficient of 0,68 and constant value of 3.43. It means, in every step-up input frequency of $1 \mathrm{~Hz}$, the pump flows 0,68 LPM of fluid. This characteristic value would be useful for open-loop-control and user interface programming in next step of development.

\section{REFERENCES}

G. K. McMillan and M. Al-Khalifah, "Control valve versus variable speed drive for flow control." International Society of Automation (ISA), North Carolina, 2013.

[2] M. Ciontu, D. Popescu, and M. Motocu, "Analysis of Energy Efficiency by Replacing the Throttle Valve with Variable Speed Drive Condensate Pump from E.C. Turceni," in 3rd International Symposium on Electrical and Electronics Engineering (ISEEE), pp. 293-297, 2010.

[3] R. Camoirano and G. Dellepiane, "Variable frequency drives for MSF desalination plant and associated pumping stations," Desalination, vol. 182, pp. 53-65, May 2005.

[4] R. Saidur, S. Mekhilef, M. B. Ali, A. Safari, and H. A Mohammed, "Applications of variable speed drive ( VSD ) in electrical motors energy savings," Renew. Sustain. Energy Rev., vol. 16, no. 1, pp. 543-550, 2012.

[5] N. Khalid, "Efficient energy management : is variable frequency drives the solution," Procedia - Soc. Behav. Sci., vol. 145, pp. 371-376, 2014.

[6] R. Dobra, A. Avram, D. Pasculescu, and M. Risteiu, "Variable frequency drive (VFD): AC motor control," Petrosani: Editura Universitas, May 2019.

[7] D. Oktavianto, W. Nugroho, T. Soehartanto, and T. A. Wibowo, "Performance of Water Pump on Distribution and Transmission Process using Variable Speed Drive,” J. Eng., vol. 6, no. 2, pp.
C. Tan, Z. M. Feng, X. Liu, J. Fan, W. Cui, R. Sun, and Q. Ma, "Review of variable speed drive technology in beam pumping units for energy -saving," Energy Reports, vol. 6, pp. 2676-2688, 2020.

[9] Application Guide Variable Frequency Drives in Retrofit or New Applications, vol. 3306. Toronto: Yorkland Controls Ltd., 2005. 